\title{
Acute pulmonary edema complicating triplet pregnancy-A Case report
}

\author{
Dr.V B Bangal ${ }^{1}$, Dr.Pravin S Thorat ${ }^{2}$, Dr.Nisarg H Patel ${ }^{3}$, Dr.Amitabh L Sahoo ${ }^{4}$ \\ 1.Professor 2. Assistant professor 3. Postgraduate student 4. Postgraduate student \\ land 3. Dept.Obst-Gynecology,2 and 4. Dept. Anesthesiology and critical care \\ Rural Medical College, Loni, Ahmednagar, Maharashtra State.413736
}

\begin{abstract}
The incidence of triplet pregnancies is on rise due to increase in the use of fertility enhancing drugs for assisted reproductive techniques .Triplet pregnancies are associated with adverse maternal and fetal outcome. There is many fold increase in the risk to the pregnant woman due to associated medical complications like anemia and hypertension. Acute pulmonary edema is rare but life threatening complication of triplet pregnancy. We report a case of primigravida with 32 weeks of triplet pregnancy, who developed acute pulmonary edema, secondary to pregnancy induced hypertension . She was delivered by emergency caesarean section after treatment of pulmonary edema. All three premature low birth weight babies survived after cesarean birth .Patient required admission in intensive care unit for three days after caesarean section .Patient was discharged on eighteenth postoperative day with three fully breastfed babies.
\end{abstract}

\section{Keywords - PULMONARY EDEMA, TRIPLET PREGNANCY, MATERNAL MORTALITY}

\section{INTRODUCTION}

Pulmonary edema is defined as the accumulation of fluid in the pulmonary interstitial spaces and alveoli, which prevents the adequate diffusion of both oxygen and carbon dioxide. Although an uncommon event in pregnancy, it is associated with an increased risk of maternal and fetal morbidity and mortality.[1] Several risk factors have been identified: preeclampsia or Eclampsia[1-3] use of tocolytic therapy,[4-10] severe infection,[3,8,9] cardiac disease,[11] iatrogenic fluid overload[5,11] and multiple gestation. Furthermore, the physiologic changes associated with pregnancy may predispose the pregnant patient to pulmonary edema [12-15]

\section{CASE HISTORY}

A twenty one year old unregistered primigravidas was referred by private practitioner as a case of triplet pregnancy of 32 weeks gestation with threatened preterm labour and mild pregnancy induced hypertension for safe confinement in the institution. She was a registered case with the referring gynecologist and had regular antenatal checkups in private hospital. She had undergone prophylactic cervical encirclage operation in fourth month of pregnancy .She had received two units of blood transfusion for treatment of anemia seven days before admission to this hospital .Present pregnancy was a spontaneous conception without intake of any fertility enhancing drugs or use of any assisted reproductive technique. She was diagnosed as a case of triplet pregnancy in first trimester by ultra sonography.

She had mild breathlessness on routine household work .General examination showed evidence of mild anemia and mild hypertension . She had mild pallor .Her pulse rate was 88 per minute ,blood pressure was $140 / 90 \mathrm{mmHg}$ and respiratory rate was 26 cycles per minute. There was no edema feet .There were no sign of cardiac failure .Cardiovascular and respiratory system examination revealed no gross abnormality .Per abdominal examination revealed tense over distended of uterus .It was difficult to know the exact presentation and position of the babies .Fetal heart sound could be located with difficulty by Doppler.

In view of the nature of high risk factors, she was hospitalized in obstetric critical care unit .Her investigations revealed hemoglobin of 8.3 grams percent ,total leucocyte count was 9,300, Platelet count was 1,50,000/cu mm. Peripheral blood smear showed picture of microcytic hypochromic anemia.Her MCV, MCHC, MCH and RDW values were suggestive of iron deficiency anemia .Her bleeding time, clotting time, prothrombin time ,INR values were within normal limits .Her renal and liver function tests were normal .She had hypo protinemia .Her serological tests for syphilis ,hepatitis B and HIV were non reactive .Obstetric ultrasound examination revealed triplet pregnancy of 32 weeks gestation with first baby in breech presentation and other two with cephalic presentation. The estimated fetal weight of each baby was approximately 1400 grams plus minus 100 grams .It was a tri amniotic pregnancy.

She was kept in semi recumbent position and was comfortable at rest. Her vitals were monitored .Mild sedative and anxiolytic drugs were started. She had slight breathlessness at rest ,but was maintaining oxygen saturation up to 98 percent without oxygen mask. There were no uterine contractions at the time of admission. Two units of compatible blood was kept reserved for her in the blood bank. It was decided to take her for caesarean section at the onset of labour. The blood pressure remained in the range of 140 to $150 \mathrm{~mm} \mathrm{Hg}$ systolic and 90 to $95 \mathrm{mmHg}$ diastolic. After two days of blood pressure monitoring , she was put on Tablet Labetalol $100 \mathrm{mg}$ twice a day .On fourth day of admission ,in early morning, patient 
developed continuous cough and breathlessness at rest. She felt very restless due to breathlessness .Her blood pressure had shoot up to $160 \mathrm{mmHg}$ systolic and $100 \mathrm{mmHg}$ diastolic. Auscultation of lungs revealed bilateral coarse crepitations .Her oxygen saturation dropped down to 85 percent .Diagnosis of acute pulmonary edema was made. She was treated with intravenous injection of Lasix, $40 \mathrm{mg}$ and oxygen by mask. In view of the uncontrolled hypertension and development of pulmonary edema, decision of emergency caesarean section was taken .Patients relatives were counseled regarding need for termination of pregnancy. Caesarean section was carried out under general anesthesia .Patient had uterine atony following delivery of placenta .It was controlled by uterine massage and intravenous oxytocin drip. Three premature babies, each with average gestational age of 32 weeks and average birth weight of 1400 grams were delivered. Two of the three babies had good APGAR score at 1,5 and 10 minutes .One baby required endotracheal intubation. In view of the likely complications due to prematurity, babies were kept in neo natal care unit. Patient was shifted to intensive care unit for postoperative cardio respiratory management and ventilator support, if required .One unit of packed red cell transfusion was given slowly over eight hours. She continued to have signs of pulmonary edema even after surgery .Total of $100 \mathrm{mg}$ of injection Lasix was administered in divided doses, at regular intervals in first 24 hours of surgery.. Intravenous fluids were restricted .Her blood pressure shoot up to $150 / 96 \mathrm{~mm} \mathrm{Hg}$ on second post operative day. It was controlled by Tablet .Methyl dopa $250 \mathrm{mg}$ three times a day. She was given intravenous lasix $20 \mathrm{mg}$ twice daily for three days. Injection Augmentin 1.2 grams intravenous along with injection Metrogyl were started on the day of surgery .Babies were kept on intravenous fluids and oxygen by mask. Supervised breast feeding was started on fourth day of birth. From fourth postoperative day onwards,patient had uneventful postoperative period .Caesarean stitches were removed on eighth postoperative day. Patient along with her three babies were discharged on eighteenth postoperative day.

\section{DISCUSSION}

The triplet delivery rate has increased worldwide since the 1970s.[16,17] A triplet pregnancy has significant implications for the mother, the infant, the family,[18] and society as a whole.[19] Triplet pregnancies are reported to have high rates of complications,[20-22] the most common of which is preterm delivery.[21], Other important complications that occur during pregnancy are preeclampsia,[22,23] and postpartum haemorrhage.[20,22] In addition, there is a two-fold increase in risk of maternal mortality in triplets over singleton pregnancies .Many studies have reported about the increased risk of pulmonary edema in triplet pregnancy.[1,2,3,11,15] .Sudden onset of breathlessness and cough are the predominant symptoms of pulmonary edema. These symptoms may at times be attributed to over distended uterus in multifetal gestation. This can lead to delay in diagnosis and management .This delay can result in deterioration of maternal condition and maternal death .Every obstetrician must have knowledge and awareness about the precipitating factors for pulmonary edema. Admission of pregnant women with triplet pregnancies in the hospital, in third trimester of pregnancy can help to improve the pregnancy outcome .Continuous monitoring of clinical parameters for early detection of complications and preparedness for their management is essential.

Present case was referred by private practitioner for safe confinement to the institute .She had mild hypertension at the time of admission. Antihypertensive treatment was started immediately, when the blood pressure was found to be persistently high .Patient developed symptoms of severe pulmonary edema in the midnight of fourth day of admission .Junior doctor on duty considered it to be the symptom due to over distended uterus and gave symptomatic treatment in the form of oxygen by mask and propped up position .Possibility of pulmonary edema was not kept in mind. Patient became restless due to air hunger and developed severe cough and orthopnoea. Senior doctor was then called .Auscultation of bases of the lungs, revealed coarse crepitations. Her oxygen saturation had dropped to 85 percent .She was immediately treated on the line of acute pulmonary edema. Meanwhile, patient went in labour. Her cervical stitch was removed and was taken for emergency caesarean section as per the plan.

\section{CONCLUSION}

Triplet pregnancy is a high risk pregnancy .It requires continuous supervision during pregnancy and labour. Hospitalization during third trimester of pregnancy helps in prolongation of the pregnancy and reduction in complication rate .Possibility of pulmonary edema must be considered in triplet pregnancy, when there is associated pregnancy induced hypertension. Auscultation of chest is mandatory in all cases, whenever there is sudden onset of breathlessness in triplet pregnancy. 


\section{REFERENCES}

1. Sibai BM, Mabie WC, Harvey CJ, Gonzalez AR. Pulmonary edema in severe preeclampsia-eclampsia: Analysis of 37 consecutive cases. Am J Obstet Gynecol 1987;156:1174-9.

2. Benedetti TJ, Kates R, Williams V. Hemodynamic observations in severe preeclampsia complicated by pulmonary edema. Am J Obstet Gynecol 1985;152:330-4.

3. Donnelly JF, Lock FR. Causes of death in 533 fatal cases of toxemia of pregnancy. Am J Obstet Gynecol 1954;68:184-7.

4. Davies AE, Robertson MJS. Pulmonary edema after administration of IV salbutamol and ergometrine. Br $J$ Obstet Gynaecol 1980;87:539-41.

5. Hankins GD, Havith JC, Kuehl TJ. Ritodrine hydrochloride infusion in pregnant baboon sodium and water compartment alterations. Am J Obstet Gynecol 1983;147:254-9.

6. Katz M, Robertson PA, Creasy RK. Cardiovascular complications associated with terbutaline treatment for preterm labor. Am J Obstet Gynecol 1981;139:605-8.

7. Pisani RJ, Rosenow ED. Pulmonary edema associated with tocolytic therapy. Ann Intern Med 1989;110:714-8.

8. Perry KG Jr, Morrison JC, Rust OA, Sullivan CA, Martin RW, Naef RW III. Incidence of adverse cardiopulmonary effects with low-dose continuous terbutaline infusion. Am J Obstet Gynecol 1995;73:1273-7.

9. Cunningham FG, Lucas MJ, Hankins GD. Pulmonary injury complicating antepartum pyelonephritis. Am J Obstet Gynecol 1987;156:797-807.

10. Towers CV, Kaminsdas CM, Garite TJ, Nageotte MP, Dorchester W. Pulmonary injury associated with antepartum pyelonephritis: Can patients at risk be identified? Am J Obstet Gynecol 1991;164:974-8.

11. Clark SL. Structural cardiac disease in pregnancy. In: Clark SL, Phelan JP, Cotton DB, eds. Critical care obstetrics. Oradell, New Jersey: Medical Economics Books, 1987:92.

12. Benedetti TJ, Carson RW. Studies of colloid osmotic pressure in pregnancy inducted hypertension. Am J Obstet Gynecol 1979;135:308-11.

13. Metcalfe JL, Ueland K. Maternal cardiovascular adjustments to pregnancy. Prog Cardiovasc Dis 1974;16:363-74.

14. Pritchard JA. Changes in blood volume during pregnancy and delivery. Anesthesiology 1965;26:39-42.

15. Scott DE. Anemia during pregnancy. Obstet Gynecol Annu 1972;1:219-44.

16. Ward Platt MP, Glinianaia SV, Rankin J, et al. The North of England Multiple Pregnancy Register: five-year results of data collection. Twin Research \& Human Genetics: the Official Journal of the International Society for Twin Studies 2006;9(6):913-8.

17. Wood R. Trends in multiple births, 1938-1995. Population Trends 1997;87:29-35.

18. Bryan EM. The consequences to the family of triplets or more. Journal of Perinatal Medicine 1991;1:24-8.

19. Malone FD, Chelmow D, Athanassiou A, D'Alton ME. Impact of gestational age at delivery of the economics of triplet pregnancy. Journal of Maternal Fetal Medicine 1999;8(6):256-61.

20. Malone FD, Kaufman GE, Chelmow D, et al. Maternal morbidity associated with triplet pregnancy. American Journal of Perinatology 1998;15(1):73-7.

21. Devine PC, Malone FD, Athanassiou A, et al. Maternal and neonatal outcome of 100 consecutive triplet pregnancies. American Journal of Perinatology 2001;18(4):225-35.

22. Albrecht JL, Tomich PG. The maternal and neonatal outcome of triplet gestations. American Journal of Obstetrics \& Gynecology 1996;174(5):1551-6.

23. Mastrobattista JM, Skupski DW, Monga M, et al. The rate of severe preeclampsia is increased in triplet as compared to twin gestations. American Journal of Perinatology 1997;14(5):263-5. 
IOSR Journal of Pharmacy

Vol. 2, Issue 3, May-June, 2012, pp.434-437

\section{CLINICAL PHOTOGRAPHS:}

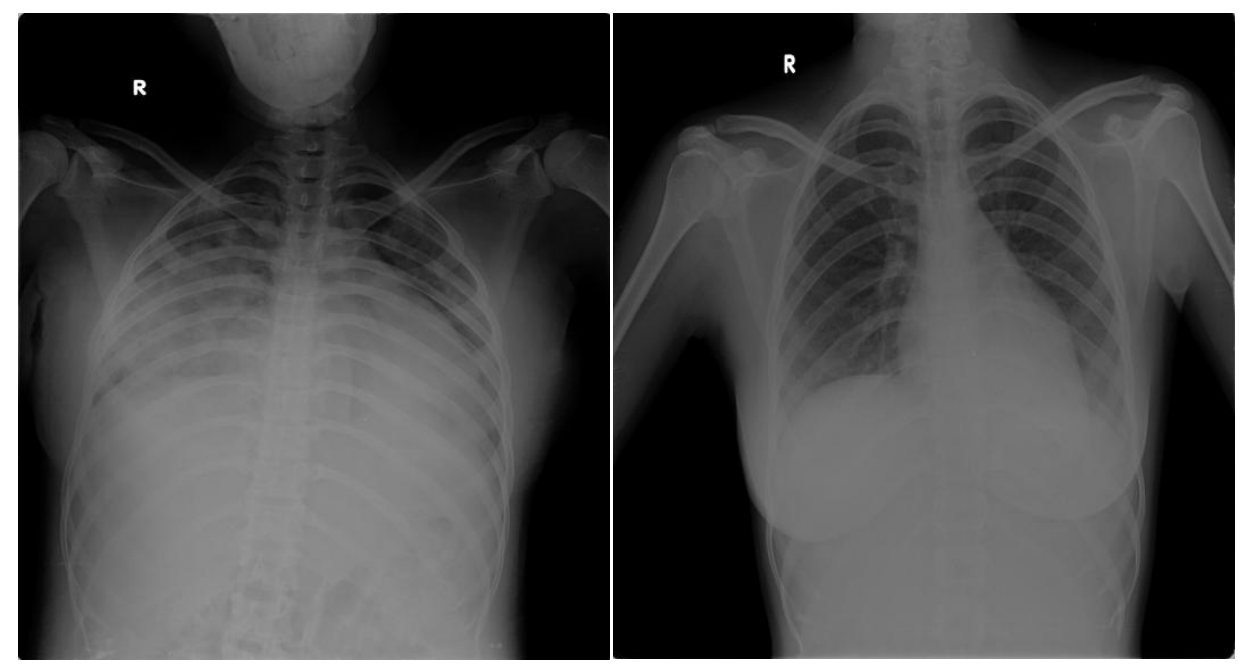

Figure 1: X-Ray Chest showing pulmonary oedema

Figure 2: X-Ray chest showing clear lung field after treatment

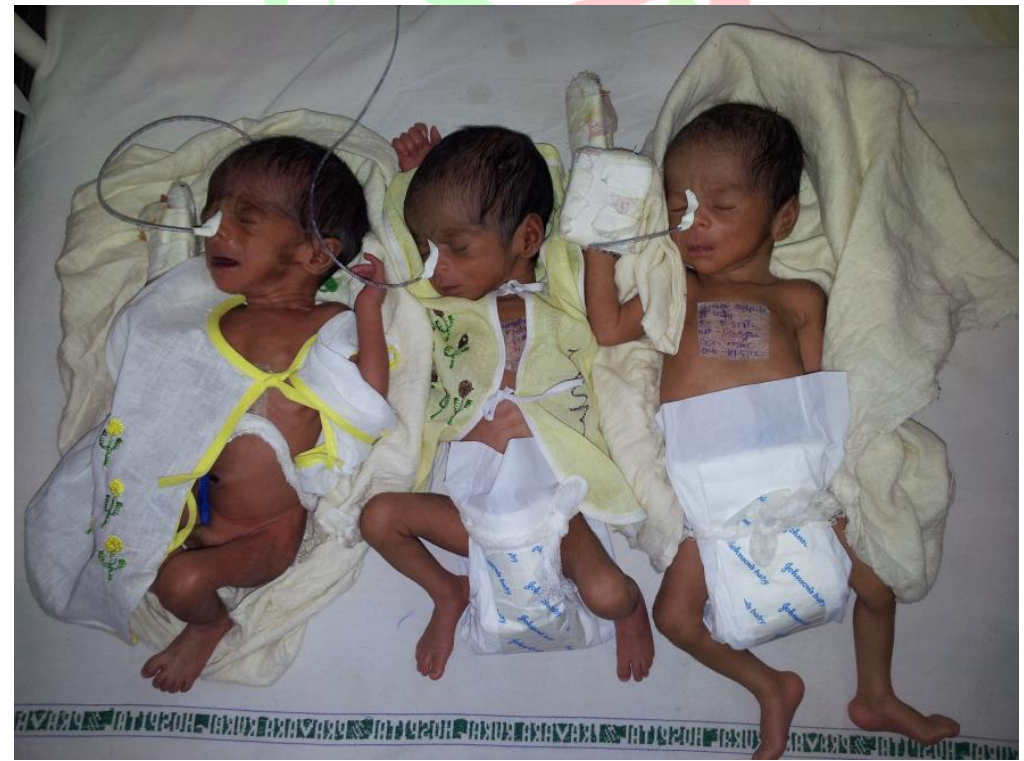

Figure 3: Photograph of Triplets 